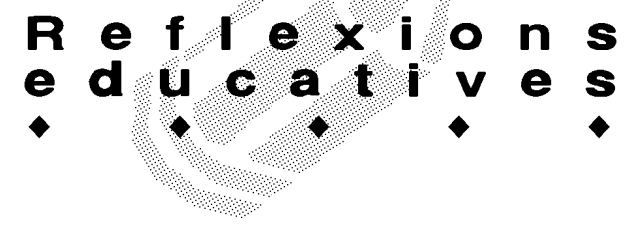

\title{
ORIENTAR L'ENSENYANÇA CAP AL DESENVOLUPAMENT DE COMPETÈNCIES. REPTES I RISCS
}

\author{
Enric Valls Giménez. Àrea de Psicologia Evolutiva i de l'Educació. URV
}

Hi ha diverses maneres d'abordar la qüestió de què hi ha al darrere del moviment per fer estudiants competents, o d'una formació basada en el desenvolupament de competències. Mirades i anàlisis crítiques que parlen d'excel-lència, de competitivitat, de resposta a condicionants mercantilistes, de resposta a noves maneres de ser i fer dels estudiants d'avui, d'ajustament a exigències d'un món canviant o, simplement, que estem diem el mateix que abans però ara amb altres vocables.

La nostra mirada crítica vol centrar-se en la qüestió entorn de la qual creiem que gira el més fonamental de l'orientació de l'ensenyança cap al desenvolupament competencial. Entenem que, malgrat ser plantejada mil i una vegades, la pregunta sobre què val la pena ensenyar i aprendre és la qüestió decisiva que mou aquesta orientació de l'ensenyança. Intentar respondre, doncs, a la pregunta de què s'hauria d'oferir en l'escolaritat perquè els ciutadans joves poguessin seguir aprenent $i$ integrar-se satisfactòriament en la societat que els toca viure està a la base, al nostre entendre, del conjunt de decisions implicades en un enfocament de l'ensenyança basada en competències.

\section{Per què ara toca parlar de competències?}

Però aquesta pregunta sobre el que cal ensenyar i aprendre no és, en efecte, una pregunta que els professionals de la docència no deixin de fer-se cada dia, de manera més o menys explícita. Una resposta educativa coherent, en qualsevol instància, implica anar revisant contínuament la selecció que s'ha fet dels continguts amb què es concreten les intencions educatives del moment, allò que els grups humans i socials esperen que compleixi l'educació i, en conseqüència, anar actualitzant i adaptant el que s'ensenya i aprèn, de manera constant i sistemàtica, en funció de les noves necessitats i avenços culturals i humans. Llavors, per què ara sembla que emergeix amb més força aquesta qüestió?

Se sap que en temps de reformes educatives (i hi estem ficats des de fa temps), al costat de canvis que afecten l'estructura del sistema, o el seu funcionament, sempre se'n pretenen d'altres que afecten la proposta dels continguts curriculars. Però entenem que les competències no apareixen ara en els currículums com una simple disposició de política educativa. La raó caldria buscar-la més en el fet d'estar vivint en una societat acceleradament canviant, on apareixen molt ràpidament noves i urgents necessitats de formació que esperen ser ateses i resoltes per la institució clau per a l'educació dels ciutadans d'avui. Així, a l'escola se li vénen reclamant sense gaires miraments, per exemple, que ensenyi a aprendre, a prevenir i resoldre conflictes, a parlar llengües, a fer persones hàbils en l'ús de les tecnologies, a dominar els discursos específics de totes les matèries per poder interpretar millor la realitat, a fer ciutadans inserits en els grups als quals pertanyen, a comprometre's en la defensa de valors, a viure de manera solidària, etc.

Davant d'exigències urgents com aquestes, que s'afegeixen a les tradicionals d'ensenyar els fonaments $i$ els instruments de la cultura, què es pot fer perquè l'escola no deixi de complir amb les seves obligacions? Una solució seria estirar com una goma el currículum i l'horari escolar, afegint-hi més i més; però, és inimaginable estirar-los fins a l'infinit. Una altra solució seria equilibrar racionalment el currículum, reduint o eliminant continguts, per donar cabuda a uns de nous que surtin al pas de les demandes actuals. El clamor popular sembla, però, reclamar tot just el contrari, que calen més hores per a matemàtiques -que diuen que el país en va fluix-, per a filosofia, per a música, per a educació física, per a matèries artístiques, per a cultura clàssica, per a llengua i literatura... Per tant, més que reduir o eliminar, el convenient seria comprimir, estrènyer el currículum perquè hi cabés tot. Males experiències hi ha quan s'ha actuat així: es va de pressa, es deixen temes o es tracten de manera molt superficial sense que els estudiants puguin arribar a trobar-hi significat $i$ sentit, es converteix en crèdits variables o optatius quelcom que seria ben comú i troncal, no es poden fer gaires coses més que explicar la lliçó, etc.

Admetent que equilibrar els currículums podria ser una solució, queda el dubte de si, davant els canvis del món actual, la formació dels ciutadans joves passa encara per la transmissió i apropiació de coneixements específics, tan tancats encara en matèries o disciplines, tan acceleradament caducs, o ha de canviar la manera 


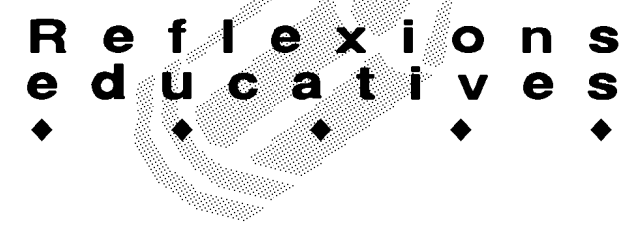

de preparar-los per a la vida i per seguir aprenent. Es pot entendre que ensenyar per al desenvolupament competencial és una opció decidida per ajudar a formarse d'una altra manera.

Ensenyar perquè els estudiants es facin competents voldria dir que s'enganxa molt més l'escolaritat o la vida acadèmica amb les necessitats principals que puguin tenir com a persones, estudiants, ciutadans, futurs professionals, que se situa qualsevol coneixement en la perspectiva de la seva funcionalitat. El canvi implica reorientar l'ensenyança per assegurar la realització d'aprenentatges cada cop més significatius i amb sentit -com venim reclamant des de fa uns temps-, per fer persones capaces d'usar més allò que aprenen, de manera que el coneixement escolar valgui per la seva potencialitat per esdevenir acció i no només per ell mateix, que serveixi per resoldre problemes i situacions de la vida. La formació basada en el desenvolupament competencial, assegurant la capacitat de fer un ús funcional, aplicat, pràctic, útil dels coneixements per resoldre situacions diverses és potser la solució més ajustada davant els problemes i reptes que suposa accedir avui al coneixement.

\section{Què suposa treballar per desenvolupar competències}

L'anterior és només el rerefons conceptual que aporta informació, sens dubte, sobre intencionalitats educatives, o sobre la manera general d'abordar canvis curriculars. Però no diu gaire cosa encara sobre el dia a dia, què fer per avançar cap al desenvolupament competencial, quins canvis calen en la manera de programar, d'ensenyar i aprendre, d'estar a classe, d'avaluar, de funcionar en els centres...

Ens hem de preguntar, doncs, per on es pot començar, quines són les decisions i actuacions bàsiques per poder reenfocar la formació orientant-la cap al desenvolupament competencial, si n'hi ha unes més obligades que altres.

Hem vist que ha existit (en els esborranys de nous currículums de l'educació obligatòria, en la preparació de l'accés de les universitats a l'espai europeu) una certa insistència per començar a treballar fent la traducció a nova terminologia del que consta en els actuals plans docents o programacions, o fent uns llistats de les competències de tot tipus (específiques, genèriques, disciplinàries, professionals, acadèmiques, personals...) que puguin servir com a punt de partida del desenvolupament curricular. Aquest inici -benintencionat, sens dubte- és enganyós, perquè fa perdre el temps en quelcom poc important com és la formalització d'elements no gaire decisius de l'experiència; una tasca que, en tot cas, sempre hauria de ser el darrer a fer. Per una banda, pot ser inoperant el treball de compondre fórmules diverses per referir-se al mateix ( ¿no ha de ser necessàriament el mateix un llistat d'objectius educatius que un llistat de competències a desenvolupar, ni que es digui amb paraules diferents?) i encara és molt menys operatiu disposar d'una llista de vuitanta o noranta competències amb la pretensió que pugui guiar la planificació i desenvolupament del currículum.

Des del nostre punt de vista, hi hauria tasques més peremptòries a dur a terme a l'hora de plantejar l'enfocament de l'ensenyança vers el desenvolupament competencial dels estudiants. N'assenyalem algunes:

- Generar un consens entre els docents sobre el significat de les competències, perquè tothom coincideixi en les intencions educatives.

- Generar un consens entorn de les característiques que haurien de tenir els contextos educatius i les pràctiques educatives que busquen promoure el desenvolupament competencial (formes d'interactuar, ajudes que es presten, activitats principals, formes d'accés a la informació, formes d'avaluació, formes d'organització).

- Resituar les actuacions dels estudiants i dels professors en els contextos educatius on es treballen les competències, des del supòsit que ensenyar per a l'acció demana altres situacions, altres activitats i altres tasques d'aprenentatge i ensenyança.

Aquestes tasques caldria plantejar-les al mateix temps que es fa adonar que el treball com a docent, implícitament o explícita, ja conté molta intenció i molta pràctica vers el desenvolupament competencial dels estudiants i que, per tant, més que una transformació radical del mateix treball, el que s'ha d'intentar és sistematitzar, integrar o orientar més decididament en una direcció determinada la dinàmica de l'aula.

En el present article ens referirem globalment a les tasques que acabem de proposar com a prioritàries

\section{El significat del terme competència}

En la vida quotidiana són diversos els significats que té el terme competència ("Les competències pendents de traspassar...", "La competència que hi ha en aquesta classe...", "En funció de les competències que m'han estat atribuïdes...", "És poc competent..."), tots relacionats, d'alguna manera, amb l'etimologia de la paraula, que proposa una doble idea: per una banda, la idea de rivalitat, baralla, disputa; per l'altra, la idea d'aptitud, idoneïtat, incumbència. (De com-petere: convergència, confluència, congruència).

Tal com l'estem entenent, amb el concepte de competència es fa referència, fonamentalment, a actuacions de la persona, i concretament a la capacitat d'actuar i 


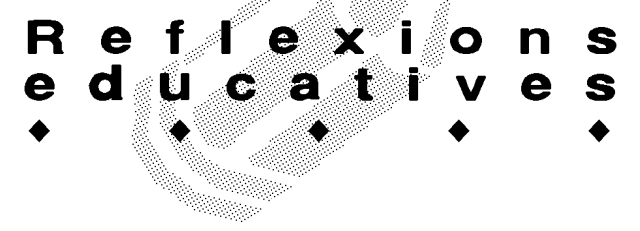

sortir-se'n amb èxit o eficaçment en la resolució de determinades tasques, exigències o demandes que planteja la vida. La persona competent té una força, té el poder d'actuar eficaçment; a més, la competència confereix a l'acció una legitimitat: te'n fies, acceptes l'actuació de la persona competent. Com es veu, treballar per al desenvolupament competencial dels estudiants voldrà dir assegurar que ells aprofiten els aprenentatges per fer-se poderosos i eficaços, i legals.

\section{Què fa la persona competent que no faci la no compe- tent?}

La persona competent demostra, per damunt de tot, que és capaç de mobilitzar adequadament determinats sabers personals en aquelles situacions que els demanen.

Ser competent és, per tant, el resultat final d'un procés de desenvolupament en alguna competència, tot i que es poden assenyalar graus de competència al llarg d'aquest procés. Amb el terme mobilitzar ens volem referir a l'activació, la posada en marxa general de determinats sabers per a l'acció. Si preferim el terme sabers és perquè considerem que els que s'inclouen en la competència són de tot tipus i procedència: coneixements escolars i acadèmics, capacitats i disposicions personals, habilitats pràctiques, informacions diverses, saber fer, poder fer, voler fer... Una persona competent és capaç, alhora, de resoldre eficaçment qualsevol situació -coneguda o novedosa, estratègica o rutinària, d'aprenentatge o d'inserció en la vida quotidiana-, on es reclami la corresponent competència.

Qui és competent en tecnologia, expressió plàstica, resolució de problemes, economia, control emocional... és capaç d'activar i aplicar conceptes, procediments, disposicions personals, informacions, etc. mitjançant els quals es dóna una resposta eficaç a les exigències de determinades situacions. Qui és competent per saber demanar coses sap fer-ho eficaçment quan es tracta de sol-licitar ajut a un desconegut, de convidar un superior

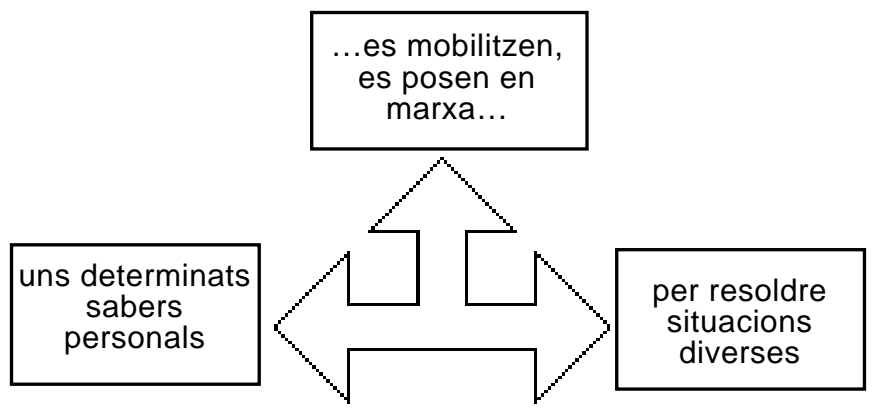

SER COMPETENT a rectificar, de convèncer un parent que et deixi quelcom valuós, de demanar que et deixin descansar aquells que fan soroll... Igualment, un lector competent és aquell que duu a terme eficaçment les activitats cognitives, estratègiques, afectives... implicades en la lectura, amb diferents tipus de textos, davant d'un gran auditori, en la intimitat...

Aquests tres elements (activació apropiada, sabers personals, demandes de les situacions) cal tenir-los presents de manera conjunta quan es pensa en les competències. Repassem, a continuació el significat $i$ característiques de cada un d'aquests tres components de les competències.

Ser competent implica disposar d'uns sabers que són suficients, potents, eficaços, que asseguren l'èxit, contribueixen a obtenir resultats valuosos

No hi ha guanys competencials sense sabers en els quals es fonamentin, de manera que seleccionar o reconèixer els sabers que componen la competència és una tasca fonamental.

Quan es parla de competències bàsiques, s'hauria d'entendre que els sabers que les componen són els essencials; és a dir, aquells que defineixen en l'essència què comporta llegir, escriure, solucionar problemes, autoregular-se, cooperar, mesurar, dur a terme projectes... Els sabers bàsics tenen un grau elevat d'universalitat i generalitat perquè s'apliquen a un ampli ventall de contextos i àmbits rellevants; són sabers, per tant, indispensables per a totes les persones per resoldre satisfactòriament problemes i situacions d'alt valor personal. Però orientar l'ensenyança per al desenvolupament competencial no vol dir preocupar-se només perquè s'assoleixin les competències bàsiques o essencials: una cosa són les competències i una altra el grup de les competències bàsiques.

En general, els sabers competencials -suficients, eficaços, valuosos...- provenen de diverses fonts, s'adquireixen aquí i allà, no només de l'aprenentatge formal i induït expressament (aprenentatges de continguts factuals, conceptuals, procedimentals, actitudinals i valoratius), sinó també a partir del que s'aprèn en l'experiència quotidiana, en les interaccions amb altres i en comunitats més àmplies. Aquesta procedència variada i diversa per a cada persona és el que acostuma a dificultar un complet treball de desenvolupament competencial quan aquest es programa en contextos instructius.

Encara que es pugui pressuposar que els currículums i plans acadèmics ja contenen sabers per a l'acció d'aquestes característiques, la planificació del treball per al desenvolupament competencial requerirà sempre una tasca consensuada entre els docents per identificar 


\section{$\begin{array}{lllll}R \text { eftce } & \text { i o n s } \\ \text { e d u c a t i v e s } & \end{array}$}

i ressaltar el conjunt dels sabers que les componen. Pot ser profitós, en aquest sentit, reunir-se per acordar una definició de la competència en qüestió on s'enumerin els seus components fonamentals i preveure, també, quines actuacions esperades de l'alumnat demostrarien l'adquisició de la competència. Perquè la decisió sobre els trets definitoris de les competències no fos un simple recull del que a cadascú li pot semblar bonament, estaria bé procedir amb rigor contrastant el treball que es va fent amb alguns models elaborats (sobre els sabers implicats en les activitats de llegir, de compondre textos, de resoldre problemes, de fer de mestre, de fer d'assessor...).

Si fer-se competent implica, primer, apropiar-se de recursos necessaris per a l'acció, llavors ensenyar per a la competència -en allò que està a les mans dels docents-consistirà a procurar expressament la facilitació dels aprenentatges referits a aquests recursos, d'acord amb els criteris didàctics apropiats, segons si es tracta de sabers conceptuals, de destreses, valoratius, etc. Es pot entendre que l'organització de la formació en matèries, àrees, disciplines, tallers, assignatures, respon a aquest objectiu de facilitar que s'aprenguin bé els recursos que fonamentaran l'acció. Ara bé, no aniríem en la bona direcció de procurar el desenvolupament competencial si aquests sabers seguissin així d'aïllats i fragmentats com fins ara. Que estigui tan arrelada en els nostres contextos formatius la tradició d'agrupar els sabers en disciplines pot ser un greu inconvenient per als canvis, si no es reinventen i fomenten altres formes organitzatives que afavoreixin la integració dels sabers per orientar-los a l'acció.

\section{Ser competent vol dir saber mobilitzar adequadament els recursos per actuar}

Si ser competent implica sovint ser savi, el contrari no és cert: un savi no és necessàriament una persona competent. Un pou de ciència en anatomia no és encara un cirurgià; un erudit en dret no és encara un advocat; un excel-lent en les assignatures d'una carrera no és encara un bon professional. Per tant, la competència se situa una mica més enllà dels sabers, tot i suposar-los; amb els sabers no n'hi ha prou.

La persona competent és la que activa els diversos sabers de manera integrada o combinada, com si es tractés d'un coneixement global: una simple suma o acumulació de sabers no és mai una competència. Que disposis de molts conceptes, destreses, informacions, etc. no et demostra competent mentre no els sàpigues usar per actuar. Un pot ser molt hàbil en determinats

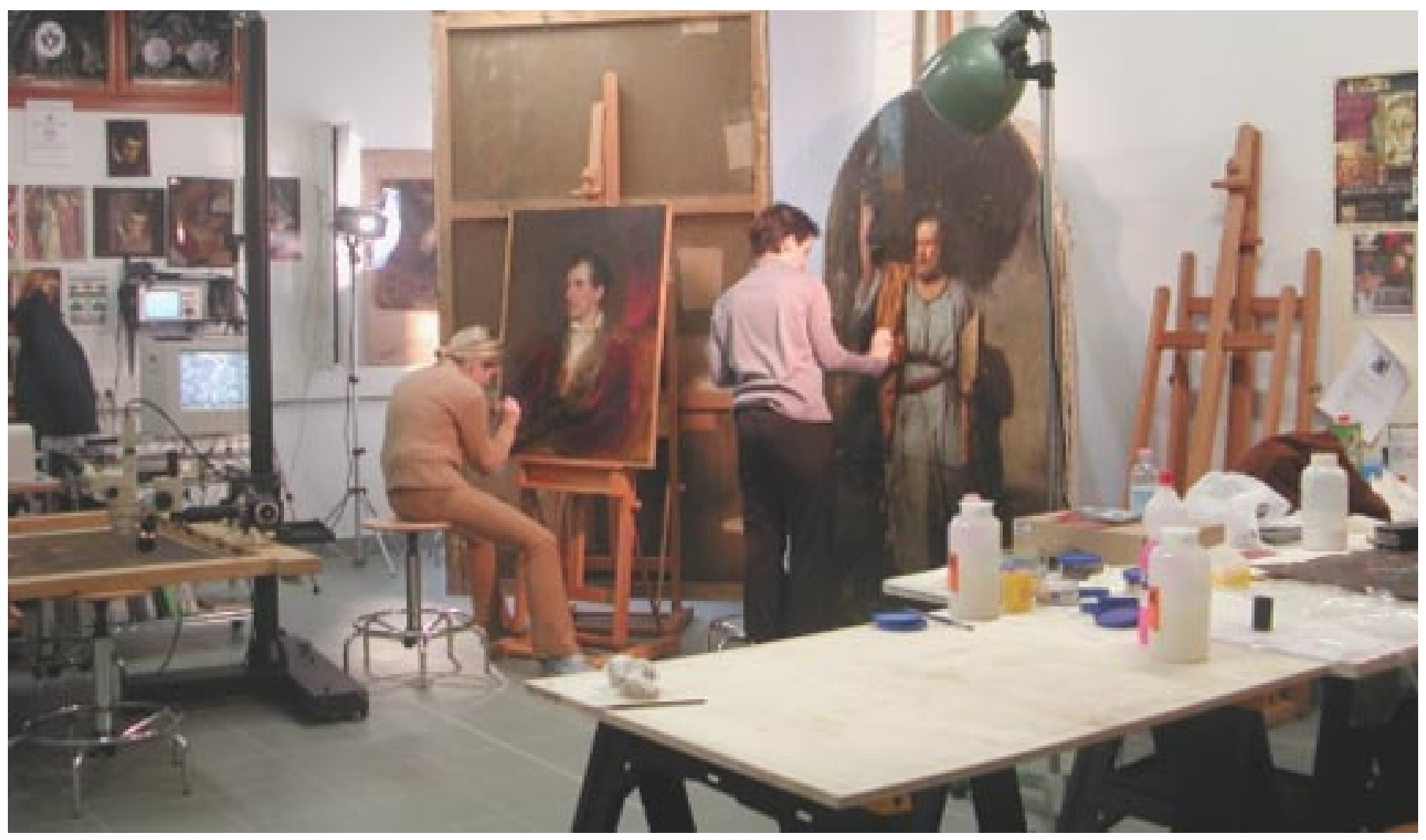




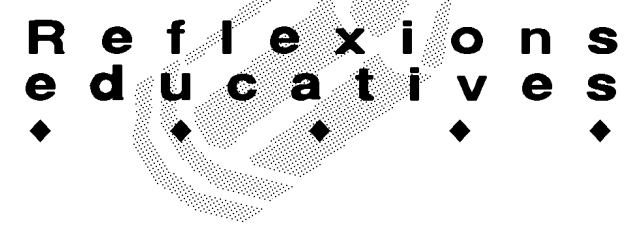

camps, però no serà competent si les seves habilitats no s'acompanyen alhora de teoria o de valoració. Allò que potser més indica l'etimologia de la paraula $(\mathrm{com}$ petere)és precisament això, la convergència, integració, confluència en un tot d'un conjunt de components.

Aquesta activació dels sabers implicats esdevé, tanmateix, oportuna, estratègica, intencionada, com a resultat d'haver reflexionat i controlat el que està passant. Es tracta, igualment, d'una mobilització personal dels recursos, sense que t'hagin d'indicar què fer, per què fer-ho, quan fer-ho, com fer-ho.

A qui fa una simple aplicació mecànica o rutinària de coneixements no li diem competent; és competent qui davant d'una situació particular és capaç de construir en aquell moment un projecte d'acció que pot abastar, entre altres, la identificació de la tasca, de les seves exigències $i$ condicionants, adonar-se dels recursos de què es disposa, decidir les accions a fer, executar-les amb eficàcia, comunicar el resultat de manera entenedora... La persona que, per exemple, sap influir molt en altres persones és aquella que mobilitza de manera integrada i personal recursos com aquests: calcular anticipadament el possible impacte de les seves paraules i accions; seleccionar les paraules i accions amb més probabilitats de produir l'efecte desitjat; escollir amb cura el moment en què s'emprenen les accions per assegurar la seva eficàcia...

Dient-ho amb altres paraules, apropar-se a la competència és un exercici, sobretot, no d'aplicació de regles, de comportaments identificats prèviament, sinó més d'usos estratègics de coneixements, de decidir el millor entre possibilitats, d'encertar. Al nostre entendre, això és el que caracteritzaria més la persona competent.

$\mathrm{Si}$ abans reclamàvem consens per decidir sabers potents que guiessin l'acció, ara encara sembla més pertinent reclamar-lo per dissenyar o revisar formes organitzatives, metodològiques, avaluatives en la docència que facilitin la mobilització dels sabers de forma integrada, reflexionada, estratègica.

Quan parlem d'això no estem pensant necessàriament en grans canvis quant a l'espai, els horaris, els escenaris educatius, els contextos tecnològics, els materials curriculars (que alguns n'hi ha d'haver, és clar, com dèiem abans), sovint difícils de plantejar i obtenir. Promoure mobilitzacions generals i estratègiques dels coneixements a les aules i als centres passa, sobretot, per intervencions didàctiques més simples i a l'abast, un decàleg de les quals ens atrevim a enumerar aquí:

- Orientar amb més claredat sobre què ha de fer l'estudiant, com, per què.

- Demanar-los explícitament major implicació en l'aprenentatge (provar, revisar, decidir, rectificar, plantejar-se metes elevades, expectatives positives...).

- Ajudar en la presa de consciència d'allò què s'està fent, la reflexió sobre l'acció.

- Oferir-se com a model de pensador en acció.

- Planificar suficients situacions per aplicar i practicar allò que s'aprèn.

- Insistir a seguir aprenent i aprenent.

- Controlar de més a prop, per si convé prevenir dificultats i corregir errors.

- Crear i mantenir un clima tranquil, d'acceptació, de facilitació de les condicions d'aprenentatge, perquè s'assumeixi la responsabilitat en l'aprenentatge.

- Sortir al pas de resistències personals dels estudiants davant els aprenentatges.

- Donar molts indicadors que permetin reconèixer com a semblants situacions escolars i no escolars, per veure'n la seva utilitat i funcionalitat.

La majoria d'estratègies d'intervenció com aquestes es refereixen al treball a l'aula, perquè són les més decisives. Però mobilitzar adequadament els recursos per actuar pot demanar, igualment, introduir millores en l'organització i coordinació general del centre, dels equips de professorat, del desenvolupament curricular, del conjunt de la comunitat educativa.

I tot això aconseguir-ho i fer-ho evident en un ampli ventall de tasques, contextos i situacions possibles

Es pot dir que la competència fa referència a uns sabers que es poden aplicar en situacions reals qualsevol, conegudes i noves, complexes i senzilles, en situacions de l'entorn concret i en altres de més llunyanes. Les competències tenen un grau elevat d'universalitat $i$ generalitat, no s'esgoten en la resolució de problemes puntuals d'un àmbit específic, com seria l'aula, el laboratori, el pati, una situació real idèntica o semblant a aquella en què s'ha après el coneixement... A major desenvolupament competencial, més possibilitat de respondre eficaçment a moltes situacions i tasques.

El que es requereix per sortir al pas de situacions puntuals són, sobretot, procediments o coneixements concrets. En canvi, el saber competencial transcendeix el particular. Per això entenem que actuacions com entonar bé, pronunciar fórmules de cortesia, prendre la tensió, mesurar volums, fer una bona avaluació, etc. reclamen només simples habilitats i no haurien de formular-se com a competències. Repetim que no té gaire sentit fer llargues llistes de competències si no es refereixen a situacions on, per resoldre-les eficaçment, es reclamen no només habilitats sinó tot tipus de sabers.

Ensenyar a activar uns sabers lliures de contextos 


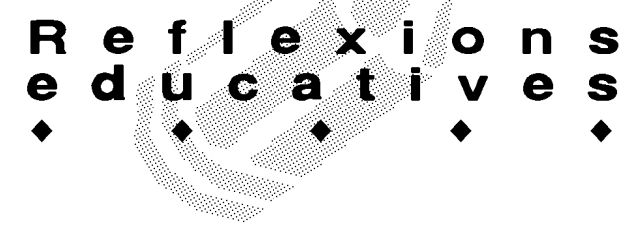

per poder-los aplicar a qualsevol context, que és el que estem dient, sí que demana expressament prendre una sèrie de mesures organitzatives en el disseny i plantejament curricular, ja que fins ara no s'ha orientat explícitament la formació en aquesta direcció.

Assenyalem algunes d'aquestes mesures:

1) Acordar amb suficient consens quines situacions educatives s'oferiran repetidament als estudiants perquè els sigui fàcil assolir i practicar els components de les competències o la mateixa competència.

En aquest sentit, el nou currículum portuguès s'han concretat algunes experiències d'aprenentatge de cara a assegurar l'assoliment de competències específiques de cada una de les àrees. Així, per a l'àrea de llengua (de Primària) s'han seleccionat aquestes:

- Audició de registres diversificats de la llengua, d'extensió i grau de formalitat progressius.

- Audició de registres de diferents varietats de la llengua.

- Activitats de producció de diversos tipus de discurs oral, d'extensió i grau de formalitat progressius.

- Activitats que facilitin la participació eficaç i adequada en situacions diverses d'interacció (debats, exposicions, entrevistes, síntesi...).

- Activitats de lectura en silenci i en veu alta de diferents tipus de textos.

- Activitats de consulta de material escrit per localitzar informació o per transformar el coneixement.

- Activitats d'escriptura usant materials i suports variats, amb el recurs d'instruments que assegurin la correcció de l'escrit.

- Activitats de composició de diferents tipus de textos.

- Activitats d'identificació i descobriments d'unitats, regles i processos de la llengua.

- Activitats de reflexió sobre la qualitat lingüística i l'adequació dels productes orals i escrits de cara a l'autonomia i autoregulació per a cada competència.

2) Assegurar la continuïtat del treball de les competències al llarg dels diferents nivells, cursos, cicles, etapes educatives..., perquè el desenvolupament competencial se situa en un contínuum i és qüestió d'anar aconseguint graus més elevats de competència.

Caldria atendre, llavors, alguns criteris de seqüenciació o de gradació en el desenvolupament de la competència. Servirien, en aquest sentit, criteris generals de seqüenciació de l'aprenentatge i l'ensenyança com assegurar que es va avançant des del més general, concret i simple al més particular, abstracte i complex, o que es progressa des de la sensibilització cap a la sistematització i l'automatització.

En el treball de la Secció VII de la Conferència Nacional d'Educació s'han fet servir els següents criteris per ordenar el progrés competencial en l'àmbit lingüístic:

- L'atenció a condicions de realització i d'èxit on emmarcar la competència lingüística, cada cop més rellevants.

- La consciència i control de la situació, ajustantse cada cop més intencionadament a les condicions de la situació comunicativa.

- L'atenció a aspectes de la interacció comunicativa cada cop més específics, de més detall, 0 de més abast.

- El compromís, la presa de decisions personal, la implicació cada cop més espontània en els intercanvis comunicatius, en la lectura, en l'escriptura.

- El distanciament progressiu de la pròpia experiència, de contextos viscuts, presencials, o massa particulars.

- La suficiència personal en la posada en pràctica de la competència lingüística, sense necessitar tantes guies o ajudes.

- La consideració progressiva d'un nombre més

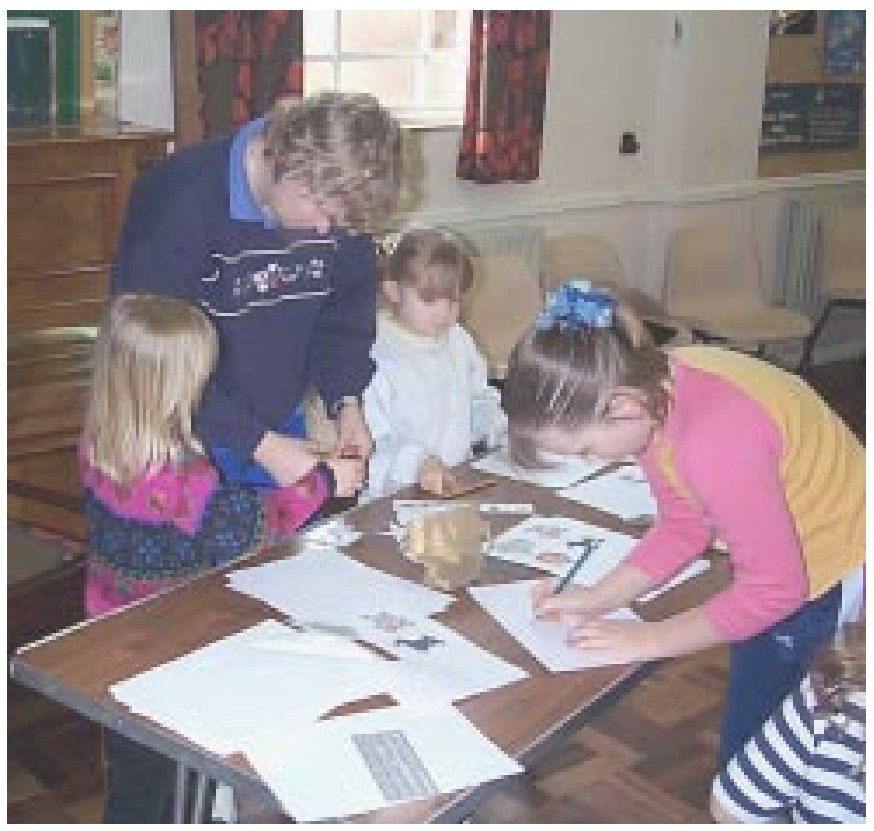




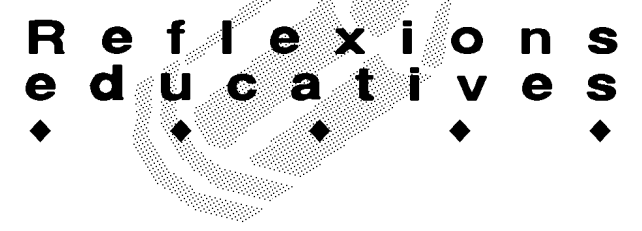

elevat de situacions i contextos comunicatius, anar guanyant nous àmbits d'actuació, d'expressió i producció oral i escrita.

- El progrés des de la unidireccionalitat a la pluridireccionalitat en els intercanvis de missatges, en les actuacions, en les intencions.

- La consideració dels continguts a tractar a un nivell que cada vegada té més complexitat: més passos o accions a realitzar, més restriccions a tenir en compte, major nombre de relacions a establir amb altres coneixements, més correcció i precisió, més organització i estructuració, més valoració.

3) Introduir en el treball escolar situacions, activitats i tasques que demanin la integració i aplicació de tot tipus de sabers.

Pel fet que les situacions formatives són eminentment artificials, de preparació, i no reals (excepte la situació d'aprendre, i només si es fa intenció expressa d'experimentar-lo), cal dissenyar expressament uns contextos d'aprenentatge més propers a la realitat, on es reclamen, efectivament, tot tipus de coneixements, uns contextos més oberts, més globals i transcendents que els específics del treball de la matèria particular.

Recordem de nou el perill que es corre -en ubicar-se actualment els coneixements en matèries i disciplines- que a l'estudiant li costi molt integrar els sabers i fer progressar les competències, si no es proposen situacions a l'efecte. En el present, plantejaments didàctics com els projectes de treball, els crèdits de síntesi, els treballs multidisciplinaris, la resolució de problemes, les anàlisis de casos, etc. ja tenen aquesta intenció, d'entrada. Però també serien interessants i profitoses altres decisions metodològiques no tan sistematitzades o ocasionals, com aquestes que s'adjunten.

4) Que qualsevol activitat prevista per a la formació de l'estudiant (activitats pràctiques, exercicis de classe, activitats d'aprofundiment, el conjunt del Practicum a la universitat, etc.) contingués explícita aquesta intenció que s'haguessin d'aplicar i integrar tot tipus de sabers per satisfer-les.

Que s'acordés un treball agrupat de molts continguts escolars que, tot i ser transversals, ara encara es van repetint en diverses matèries (per exemple: conceptes clau com els d'equivalència, mesura, canvi, organització, causalitat.., o destreses com les implicades en la comprensió de textos, en la gestió i regulació dels mateixos aprenentatges, en el tractament de la informació...).

\section{Conclusions}

No deu haver passat inadvertit que el llenguatge de les competències és un llenguatge conegut entre els docents: aprenentatge significatiu i amb sentit, usos estratègics dels coneixements, funcionalitat del què s'aprèn, formar-se per poder seguir aprenent sempre.

Ara aquest llenguatge i intencions estan arribant a tot arreu, a l'educació primària, a la secundària i a la universitària (Amb la pretensió que es pogués interpretar per qualsevol docent, del nivell educatiu que sigui, hem pretès escriure aquestes ratlles). Arreu se sent com una necessitat de redefinir la formació, els aprenentatges fonamentals $o$ els pilars del coneixement per a cada persona en el transcurs de la vida. Es vol que el coneixement escolar i acadèmic sigui útil, es pugui posar en acció, serveixi per resoldre problemes i situacions de la vida escolar, quotidiana, professional i no sigui només un coneixement formal, vàlid per a pocs contextos i problemes, i que ho sigui per al màxim de persones perquè puguin fer front a les exigències complexes amb eficàcia.

En aquest article hem volgut reclamar, també, que els aires nous que posen en primer pla l'orientació de l'ensenyança per al desenvolupament competencial no consisteixen només en llenguatges i formes. Es tracta de propostes que comprometen professionalment, que conviden a refer o revisar la pràctica professional dels docents i a reflexionar de nou sobre les responsabilitats amb què se'ls ha investit socialment.

\section{Bibliografia consultada}

AA.DD. Siglo XXI. Competencias para sobrevivir. «Cuadernos de Pedagogía», 298 (2001) 49-79.

COLL, C. Redefinir lo básico en la educación básica. "Cuadernos de Pedagogía», 339 (2004) 80-84.

Debat sobre el sistema educatiu català. Conclusions i propostes. Conferència Nacional d'Educació 2000-2002. Departament d'Ensenyament. Barcelona.

ECHEVARRÍA, B. Gestión de la competencia de acción profesional. «Revista de Investigación Educativa», 1 (2004) 7-43

OCDE. Definition and Selection of Competencies: Theoretical and Conceptual Foundations (DeSeCo). Annual Report 2001/spring 2002.

PERRENOUD, PH. L'Université entre transmission de savoirs et dévéloppment de compétences. 3r. Congrés Internacional: "Docència Universitària i Innovació". Girona. 30 de juny i 1 i 2 de juliol 2004.

VALLS, E. Competències bàsiques de l'àmbit lingüístic. Ponència en Congrés de Competències Bàsiques. Barcelona 26 i 27 de juny 2004. 